\title{
El mueble en el Perú en el Siglo XVIII: un acercamiento al modo de vida de la élite colonial
}

Gabriela Germaná

\section{Introducción}

Los muebles, objetos de larga tradición en la historia de occidente y que llegaron al Perú con la conquista española, son portadores de enunciados diversos tanto en su aspecto físico-material como en las connotaciones que se derivan de su uso. Así, si por un lado puede analizarse las características materiales y técnicas de los muebles y su valor estético; por otro, de una manera completamente sugerente, se puede obtener datos importantes sobre la cultura, el modo de vida y la manera de pensar de las sociedades que los producen y consumen.

El mueble peruano del período virreinal fue trasladado inicialmente entre los enseres de los conquistadores para poder mantener un modo de vida semejante al de su lugar de origen, y posteriormente fue realizado también por artífices locales, siguiendo muy de cerca patrones y modas europeas. La información sobre el mueble de esta época se puede obtener tanto de los documentos de archivo como de los ejemplares que se han conservado hasta el día de hoy. Sin embargo, el universo de este material de estudio se limita básicamente a los muebles pertenecientes a los grupos dirigentes de la sociedad colonial; los materiales costosos en que fueron realizados permitieron su conservación a través del tiempo y dado su carácter suntuario fueron igualmente considerados en todo tipo de registros de bienes ${ }^{1}$.

En el presente artículo se presentará el análisis de los inventarios post-mortem de algunos de los personajes más importantes de la alta sociedad civil del siglo XVIII ${ }^{2}$, representativos de los diversos grupos que conformaban la clase dirigente de la época como el del virrey marqués de Castelldosrius (1710), los de varios nobles comerciantes como Doña Rosa Juliana Sánchez de Tagle, primera marquesa de Torre Tagle (1761), don Gerónimo Angulo,

1 Al respecto, para un contexto similar como el español, Xavier Lencina apunta que “(...) la realización de inventarios post-mortem, por su propia naturaleza legal, era emprendida mayoritariamente por aquellos individuos que contaban con un patrimonio a heredar, siendo más escasos los documentos pertenecientes a sujetos con una economía más precaria." (1999: 44). Y Bartolomé Yun señala que, en los estratos más bajos de la sociedad, “(...) propensos a arreglar disputas por las buenas antes que dar lugar a procedimientos judiciales y tasaciones caros y capaces de extinguir la herencia antes de recibirla (...)", es más limitado el número de inventarios (1999: 32).

2 Una metodología de trabajo que ha demostrado ser bastante útil para relacionar la cultura material con determinados comportamientos sociales, es el análisis de los inventarios post-mortem. A través de ellos se puede obtener una serie de características de los bienes que poseía cada persona, y a partir de ello algunos aspectos de su modo de vida o, a nivel más general, del comportamiento de un grupo social. Son fuentes que permiten tratar de los niveles de vida según las diferencias sociales, y esto es posible debido a que se puede relacionar el nivel de riqueza, la condición social o el oficio con determinados modelos de consumo, cultura material o estilos de vida. 


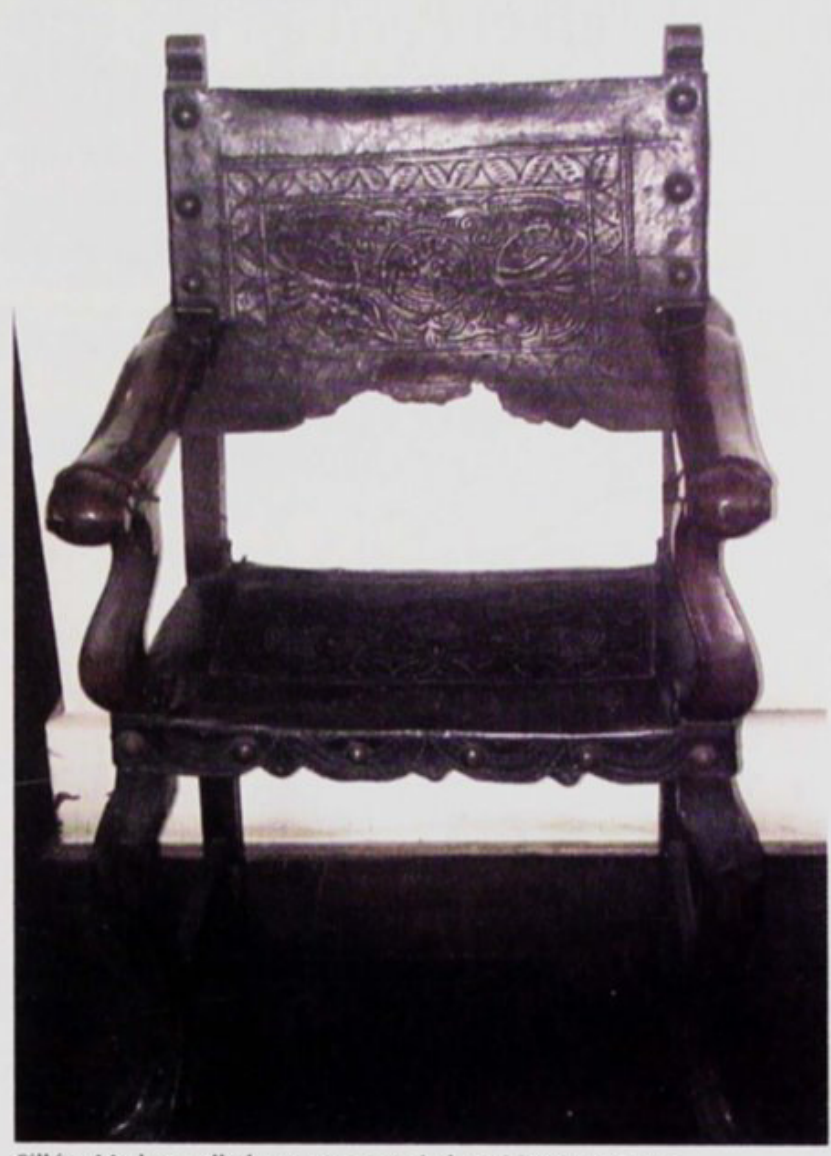

Sillón. Madera tallada y cuero repujado. $108 \times 61 \times 52 \mathrm{~cm}$. Colección MALI. conde de San Isidro (1771), Don Nicolás de Tagle Bracho, segundo Conde de Casa Tagle (1775), doña María Ignacia Carrillo y Garces, condesa de Vistaflorida (1791), y don José González Gutiérrez, primer conde de Fuente González (1806); el inventario de la Quinta Presa perteneciente a un personaje de una familia acomodada como es la del coronel del ejército real don Pedro Carrillo de Albornoz (1798); y el inventario de la casa y oficina de don Cristóbal Francisco Rodríguez, Administrador General de Temporalidades, un alto funcionario del gobierno $(1789)^{3}$.

Se buscará determinar a través de ellos algunas características estilísticas del mueble del siglo XVIII, pero sobre todo se incidirá en la preferencia por la posesión de determinadas piezas de mobiliario, la función a la que estaban destinadas y su disposición de los interiores domésticos, para señalar una serie de normas y costumbres que caracterizaban el

comportamiento del grupo más poderoso de una sociedad estamentaria como la colonial.

En relación con los ejemplares descritos en estos inventarios se incluyen las fotos de muebles que se han conservado hasta el día de hoy en las siguientes colecciones: Museo de Arte de Lima (MALI), Museo Nacional de Antropología, Arqueología e Historia del Perú (MNAAHP), Quinta Presa -propiedad del Instituto Nacional de Cultura-, Palacio de Torre Tagle -propiedad del Ministerio de Relaciones Exteriores-, Casa Goyeneche -propiedad del Banco de Crédito del Perú-, y la de Alfonso Cabrera Ganoza.

\section{El modo de vida de un virrey a inicios del siglo XVIII: entre la nueva moda afrancesada y el gusto local por lo barroco}

El inventario de Palacio de Gobierno con los bienes de Manuel de Oms de Santapau Olim Sentmenat i de Lanuza, marqués de Castelldosrius $(1710)^{4}$, nos permite conocer ciertos aspectos del modo de vida de un virrey a inicios del siglo XVIII 5 . Si bien Castelldorius deseaba reproducir formas de comportamiento de la corte de Luis XIV, que había conocido durante su estancia como embajador en Francia $(1698-1701)^{6}$, el inventario nos muestra

3 Todos los inventarios provienen de los Protocolos Notariales del Archivo Colonial del Archivo General de la Nación -el del virrey Castelldosrius nos fue generosamente proporcionado por la historiadora Nuria Sala i Vila-, con excepción del inventario de la condesa de Vistaflorida que proviene del Archivo Histórico del Instituto RivaAgüiero de la Pontificia Universidad Católica del Perú y del inventario de la Quinta Presa que transcribió Ella Dumbar Temple para la revista Documenta. Revista de la Sociedad Peruana de Historia, Año I, N 1 (1948).

4 Inventario de Bienes del Marqués de Castelldosrius. AGN, Protocolos, Diego de Castro, 1689-1719, ff. 1047 y ss.

5 En la época colonial el amoblado y la decoración del palacio eran propiedad del virrey, por lo que cada relevo suponía un nuevo conjunto de piezas (Sala i Vila, 2004). Es por ello que a partir del estudio de los bienes del palacio que presenta el inventario de Castelldosrius, podemos conocer sus gustos particulares.

6 Esta influencia se nota claramente en la introducción que él hizo de nuevos cánones artísticos como el teatro francés y la música italiana, y en la fundación de una academia literaria. Se trata de nuevas formas culturales que Castelldosrius trajo a Lima y que representaron un quiebre con la tradición española anterior. (Ídem, 2004). 
que, en general, en la decoración del palacio y en su mobiliario sigue las pautas del estilo barroco, más cercano a las preferencias locales, y el gusto afrancesado se introduce y se refleja de modo más bien mesurado ${ }^{7}$.

El ambiente público más importante del palacio era la Sala de Audiencias, cuyos muros estaban decorados con telas valiosas (una colgadura de damasco encarnado con cenefa y pasamano de seda y oro, y tres cortinas de damasco nácar con cenefa y sevillaneta de oro). En el centro se ubicaba la silla del virrey bajo un dosel, y todo el resto del mobiliario estaba constituido por numerosos asientos (12 sillas de baqueta, probablemente para los personajes más importantes, 32 sillas y 12 taburetes de suela ordinaria, 16 bancas y dos escaños ${ }^{8}$ ), lo que concuerda con la función de un espacio en el que el virrey recibía a una gran cantidad de gente. Es significativo, además, que esta sala no presentara cuadros en las paredes, probablemente para centrar toda la atención en la figura de Castelldosrius.

Otro espacio público importante es el gabinetero, lugar en el que el virrey resolvía pactos y negociaciones con personajes poderosos. En él encontramos varios escritorios ${ }^{9}$, muebles que corresponden a la función específica de este ambiente, pero que también servían para demostrar la riqueza y el poder de quien los poseía; desde el siglo XVII se habían convertido en valiosos artículos de moda, en muchos casos diseñados únicamente para su exhibición ${ }^{10}$.

No sorprende tampoco que en el gabinetero se encontrara ubicado un catrecito de madera, ya que era usual en la época que los miembros de las clases altas recibieran a las visitas destacadas recostados en sus lechos. Esta práctica se extendía al cuarto de dormir, por lo que esta habitación estaba también espléndidamente decorada"1. Según el inventario de Catelldosrius en este espacio se encontraba una de las camas más lujosas del palacio (decorada con pabellón y rodapiés de damasco carmesí), así como mesas forradas en baqueta de Huamanga, ricos escritorios y un estante con coronación de bronce. También es bastante suntuoso el segundo cuarto de dormir, el cual estaba amoblado con una magnífica cama imperial ${ }^{12}$ con cobertores de felpa y cortinas de tafetán de color verde, dos petacas doradas de Huamanga para guardar la ropa de cama y de vestir, y un cajón para las

7 Diferentes estudios sobre el arte colonial peruano han demostrado el arraigamiento que tuvo en nuestro territorio el estilo barroco, desarrollado principalmente durante el siglo XVII y que en la primera mitad del siglo XVIII derivará en lo que se conoce como "churrigueresco", es decir, un barroco más recargado. Paralelamente, durante el siglo XVIII se desarrolló en el Perú el estilo rococó que representaba el nuevo gusto establecido con la subida al trono de España de la dinastía francesa de los Borbones, aunque su aceptación fue bastante limitada por la decidida atracción local por el barroco.

8 “'(...) 'Taburete' es el asiento que hoy denominamos 'silla', es decir, uno con patas y respaldo. 'Silla' o 'silla de brazos' se denominaba a lo que hoy conocemos por 'sillón', siendo la 'silla poltrona' (...) una silla de brazos con sus costados y respaldo tapizados. (...)." (Junquera y Mato, 1999: 431). Asimismo, hay que aclarar que la "silla de brazos" es lo que comúnmente se conoce como "sillón frailero". Sin embargo, esta denominación no aparece en los inventarios, pues es un término del siglo XIX.

9 Este tipo de mueble es el que comúnmente se conoce como bargueño. Esta denominación, sin embargo, fue acuñada recién en 1872 fundamentada “(...) en una supuesta fabricación de los muebles en el pueblo toledano de Bargas o a la actividad, en la Ciudad Imperial, de un ebanista llamado Vargas. Ambos extremos no han podido ser confirmados, por lo que tal denominación es una invención del pasado siglo." (Junquera y Mato, 1999: 416).

10 “(...) Se componía de una parte superior rectangular, en la que había muchos cajones pequeños que a veces estaban ocultos por puertas, sobre un soporte; en su realización se emplearon los mejores materiales y las técnicas e innovaciones más modernas de la época. (...) la manía por coleccionar cosas, hizo de los escritorios lugares utilísimos para guardar los objetos acumulados por sus propietarios: piedras preciosas, muestras geológicas, conchas, manuscritos, monedas, medallas (...)." (Bennett Oates, 1984: 82).

11 Los textos especializados indican que los personajes de las clases altas solían recibir a sus visitas en dormitorios ostentosos o en camas lujosas que podian instalarse en diversas habitaciones de la casa. En el caso de los dormitorios, muchas veces incluso sólo tenían una función ceremonial, ya que para dormir se utilizaban pequeñas recámaras. (Lucie-Smith, 1980: 47).

12 Pensamos que se denomina así a las camas de pilares que presentan un cielo o dosel, ya que según Junquera y Mato "la cama se componía de un lecho o catre y de un cielo o imperial que podía variar mucho según la categoría del mueble." "(...) en las camas de pilares su tamaño era el mismo que el del lecho y descansaba sobre aquellos, nacidos en las vertientes de las esquinas. En las camas más modestas, el dosel era de pequeño tamaño y circular (...) constituido por una pieza de tela pendiente del techo (...)." (Junquera y Mato, 1999: 405). 


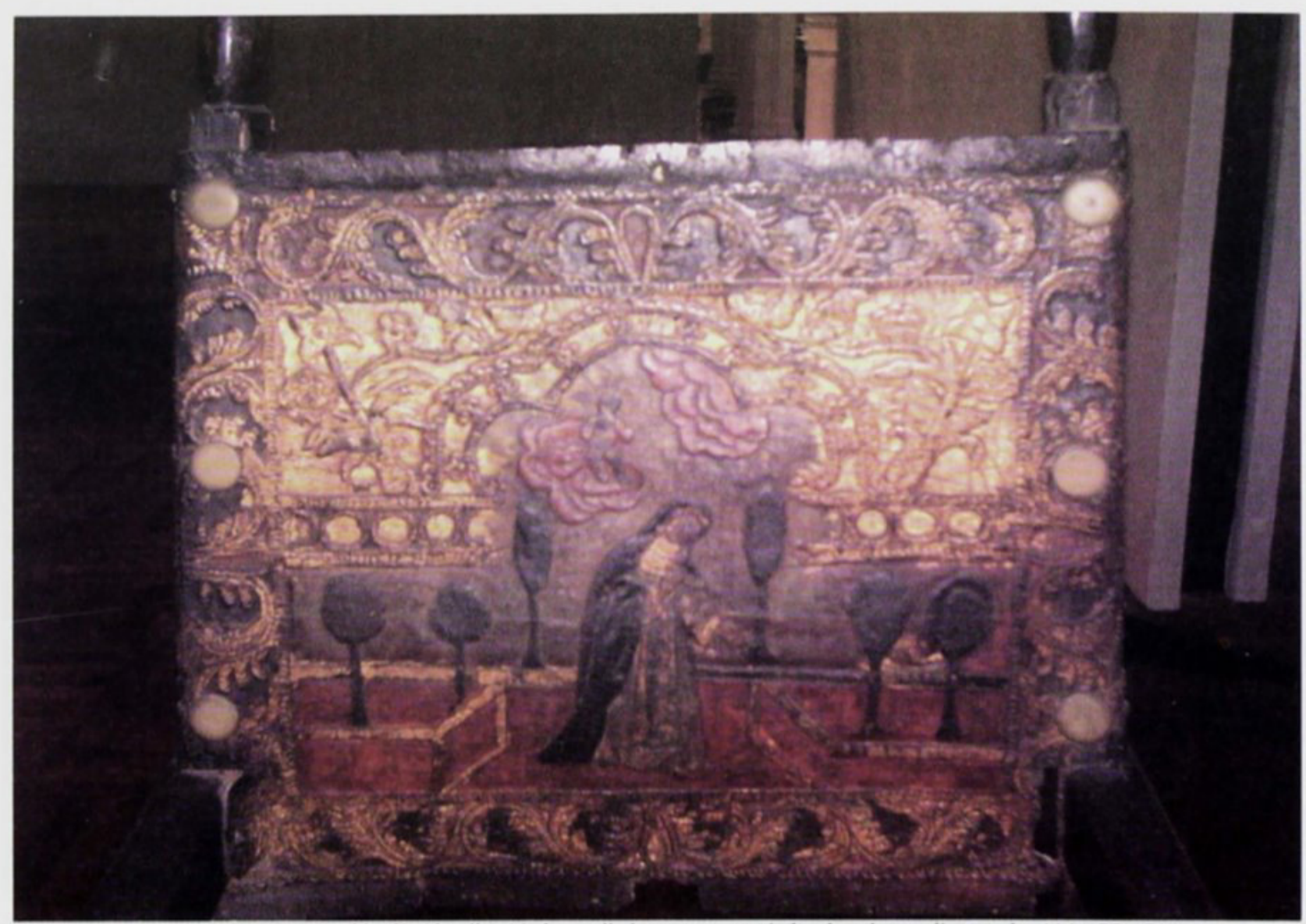

Sillón con escena de Santa Rosa en el jardín (detalle). Madera tallada y cuero repujado, dorado y policromado. 114 x 55 x 51 cm. Colección MAL.I.

joyas y alhajas. Un aspecto a resaltar en esta habitación es la presencia de siete reposteros dorados con las armas del marqués de Castelldosrius.

A diferencia del amoblado de las estancias descritas anteriormente de marcada tendencia barroca, la casina del jardín es un ejemplo característico de decoración afrancesada. Se trataba de un gran salón con diez espejos de marcos dorados y veinte consolas doradas ${ }^{13}$, y adornado con piezas de losa de la China.

Es interesante poder señalar algunas características decorativas de los muebles. De acuerdo a la acentuada inclinación barroca antes señalada, los recubrimientos de la mayoría de ellos (sillas, taburetes, mesas, escritorios, petacas) son de baqueta de Huamanga, -cueros labrados, realizados en la ciudad del mismo nombre-. Otros tipos de revestimientos de cuero, pero usados en menor cantidad, son la suela ordinaria -que en comparación con la de Huamanga, nos remitiría al cuero sin labrar-(sillas y taburetes), y la badana (una mesita y un baúl). También se encuentran, aunque con menor incidencia, tapizados de tela como la seda (un canapé y dos sillas), el damasco carmesí, y la felpa y el tafetán verde (sillas, taburetes y canapés, así como cortinas y sobremesas).

Los muebles no recubiertos estaban decorados también a la manera barroca con aplicaciones de metal (coronaciones y conchas de bronce, adornos de fierro dorado y aplicaciones de latón dorado, denominados "bronceados"), enconchados e incrustaciones de carey, marfil y concha de perla, y madera dorada. También se encuentran muebles sin forro ni decoración, que son listados como "de madera lisa", "sin forrar" o simplemente "de madera".

13Las consolas son mesas características del siglo XVIII, realizadas para estar ubicadas contra los muros y para servir como soporte de objetos decorativos (esculturas, cerámicas, relojes, candelabros e, incluso, pequeños escritorios). (Junquera y Mato, 1999: 410 y 424). 
III. El modo de vida de los nobles comerciantes: Comparación de los roles masculino y femenino en los interiores domésticos

En el virreinato del Perú la nobleza estaba conformada originalmente por el virrey, los funcionarios y acompañantes que llegaban con ellos -ricos personajes y burócratas designados para ejercer cargos importantes-, y las familias de beneméritos, descendientes de los conquistadores y de militares distinguidos en las luchas civiles. A estas últimas la corona española les había ofrecido como recompensa tierras, encomiendas, puestos públicos y títulos de nobleza. Con el paso del tiempo, sin embargo, la configuración de esta clase social fue cambiando pues muchas de las antiguas familias nobiliarias empobrecieron y perdieron su rango, mientras que numerosos linajes de comerciantes fueron amasando grandes fortunas y adquirieron el título de nobleza ya sea formando alianzas con los nobles o comprando su título a la corona española.

En el siglo XVIII, por lo tanto, el grupo más exitoso de la nobleza virreinal, especialmente en lo social, eran los nobles comerciantes, quienes “(...) no sólo son ricos mercaderes, dinámicos en su actividad principal, sino también terratenientes, propietarios de casas, de esclavos y cargos públicos de gran notoriedad, relacionados matrimonial y familiarmente con linajes de igual condición o de mayor raigambre en el medio. Son estos comerciantes, por añadidura, los que finalmente consiguen obtener la presea más codiciada del ordenamiento jerárquico de las sociedades del antiguo régimen: el título nobiliario". (Rizo Patrón, 2000:21).

En el modo de vida de la clase alta de la época hay un aspecto que el mueble permite abordar de modo sugerente: la diferencia en los roles de género que la sociedad imponía a los miembros de este grupo y que se pone particularmente en

evidencia en su comportamiento alrededor del entorno doméstico. Según estas pautas, las mujeres estaban relacionadas con la vida privada del hogar y sus tareas más domésticas, mientras que los hombres estaban vinculados a las funciones económicas y políticas, es decir, a una vida pública. El análisis diferenciado de los conjuntos mobiliarios de los personajes masculinos y femeninos, por lo tanto, nos proporcionará ciertas pautas sobre sus modos de vida asociados a la ubicación y uso de determinados muebles en espacios específicos de sus viviendas.

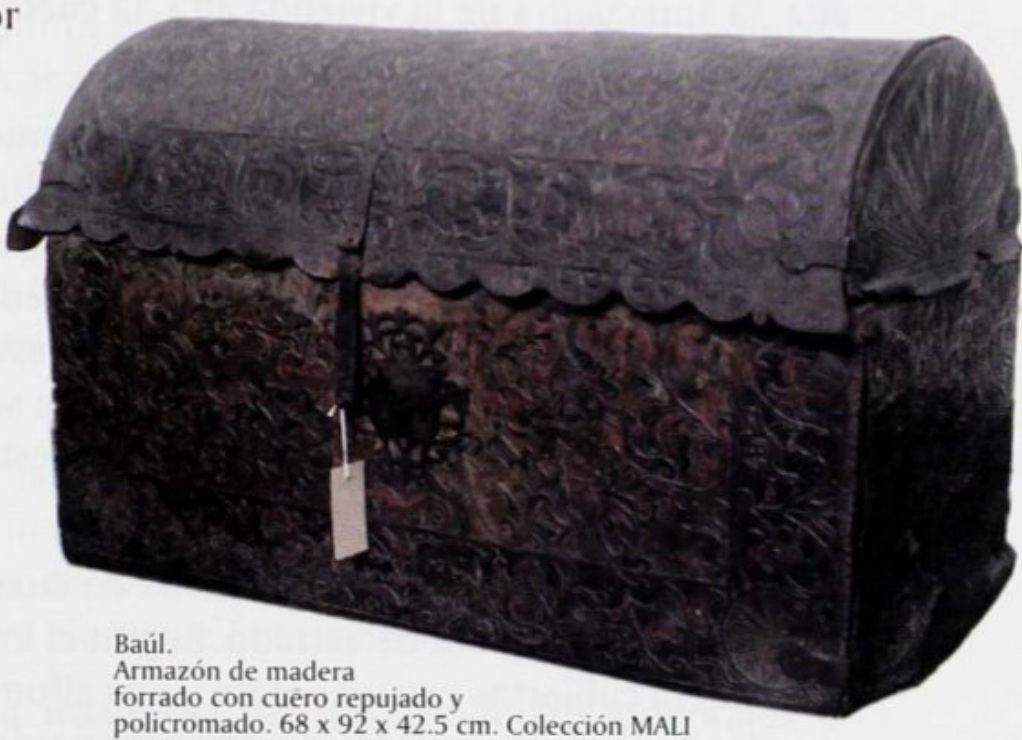

\subsection{El entorno doméstico femenino}

El análisis de los inventarios post-mortem de Rosa Juliana Sánchez de Tagle, primera marquesa de Torre Tagle $(1761)^{14}$ y de doña María Ignacia Carrillo y Garcés, condesa de Vistaflorida $(1791)^{15}$ nos permite una aproximación al modo de vida que llevaban dentro de sus residencias las mujeres de la clase dirigente de la sociedad colonial de la segunda mitad del siglo XVIII.

14Inventario y tasación de bienes de doña Rosa Juliana Sánchez de Tagle, marquesa de Torre Tagle. AGN, Protocolos,

Agustín Jerónimo Portalanza, $N^{\circ} 871,1761-1763$.

15Tasaciones de los bienes de la condesa de Vistaflorida. AHRA-IRA-PUCP, Cód.: FRAC-0152, 86 ff. 


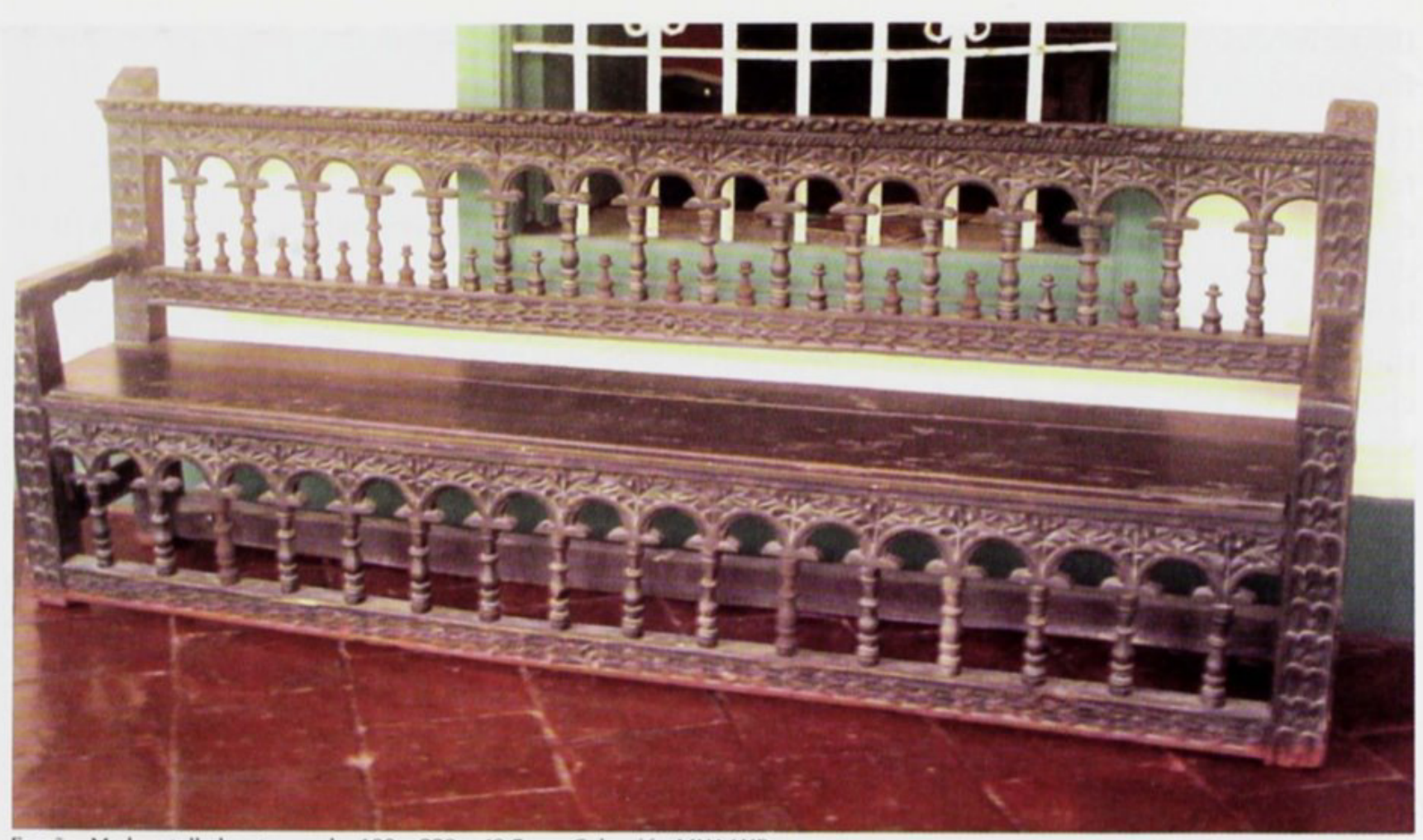

Escaño. Madera tallada y torneada. $100 \times 229$ × $49.5 \mathrm{~cm}$. Colección MNAAHP.

La vivienda de la marquesa de Torre Tagle, ubicada en la ciudad de Lima, constaba según el inventario de las siguientes habitaciones: la recámara inmediata a la cuadra, la cuadra de dormir de la marquesa, la cuadra de estrado de la marquesa, la sala, el estudio que está a la cabeza de dicha sala, un cuarto del patio, las cocheras, un cuarto de los altos de la vivienda alta, la antecuadra de la vivienda alta, la cuadra de la vivienda alta, una de las piezas de la vivienda alta.

Las únicas habitaciones que se consignan amobladas son las cuatro primeras -las demás contenían otro tipo de objetos-, lo que podría indicar que eran éstos los espacios en los que la marquesa transcurría la mayor parte de su vida doméstica: la cuadra de estrado, la sala, la cuadra de dormir y la recámara inmediata a la cuadra, todas ellas interconectadas entre sí ("... las puertas de dicha cuadra de estrado... caen a la de dormir y a la sala”). Tres de estos ambientes -la cuadra de estrado, la sala y el dormitorio- al ser espacios de recibo en los que la marquesa debía demostrar su estatus elevado frente a los invitados, destacan por su lujosa decoración.

Uno de los espacios más significativos en cuanto a las costumbres femeninas de la época, lo constituye la cuadra de estrado. Según el inventario, en ella se encontraban tres tarimas de madera cubiertas con un petate y una alfombra, con doce cojines de terciopelo carmesí, y rodeadas por un espaldar de damasco verde. Se advierte de esta manera que el uso del estrado, proveniente de la tradición de origen musulmán y adoptada en la colonia desde los primeros años, se mantiene hasta bien entrado el siglo XVIII. En él las mujeres se sentaban sobre cojines a pasar el rato durante el día realizando actividades diversas como charlar, coser, recibir a las invitadas e, incluso, comer $^{16}$.

16Sobre el estrado, Junquera y Mato explica que, "por influencia islámica, hasta el siglo XIV se mantuvo la costumbre de sentarse en el suelo sobre almohadas dispuestas encima de alfombras o guadamecíes que, para evitar la humedad, se ponían sobre un estrado de madera. Costumbre que en los reinos cristianos se puede rastrear desde el siglo X y que daría lugar a la pieza de recibo característicamente ibérica, el estrado, definido a finales del siglo XII y que sería (...) lugar especialmente femenino." (1999: 394). Asimismo, Aguiló indica que en España la costumbre del estrado, “(...), tarima de madera cubierta con una alfombra, donde las damas se sentaban al uso morisco sobre almohadones de terciopelo o guadamecí, con cajas de ébano y marfil, en los que se echaban huesos de aceitunas para dar buen olor (...)", persistió hasta el siglo XVIII (1987: 273). 
Decoraban este espacio finos objetos como una cajita embutida de concha de perla, carey y marfil, dos cajitas negras de la China con chapas de metal, cuatro taburetes de baqueta de moscovia con sus respaldos, dos escritorios de dos cuerpos embutidos en carey, marfil y concha de perla y dispuestos sobre mesas de madera. También se encontraba, sobre la basa inferior de una de las ventanas, un pequeño escritorio de tres cajones en el que se guardaban las novenas y otros libros. Las puertas de la cuadra, que daban acceso a la cuadra de dormir y a la sala, estaban cubiertas con cortinas de damasco verde.

Las cajitas, realizadas en materiales costosos, son representativos del gusto femenino de la época -se trata probablemente además de objetos suntuarios que servían especialmente a las mujeres de la élite para demostrar su prestigio y riqueza-, y la existencia de escritorios, generalmente de tamaños pequeños y muy decorados, está relacionada con la costumbre entre las mujeres de escribir cartas y notas personales.

En la sala se encontraban tres canapés recubiertos con baqueta y guarnecidos con clavos dorados, una mesa grande, dos mesas pequeñas con decoración embutida, doce sillas recubiertas con baqueta y un escritorio negro de la China. La numerosa presencia de asientos (doce sillas y tres canapés) corresponde, sin duda, a la función de recibo de este espacio. Asimismo, es necesario anotar que en uno de los muros de la sala estaba empotrado el oratorio, lo que denota la determinante presencia de la religión en el ámbito de la vida doméstica.

La cuadra de dormir al ser, como se ha indicado anteriormente, un espacio destinado también al recibo de las visitas, presenta un lujoso amoblado, entre el que destaca una imponente cama cubierta de cortinajes -"una cuja de cocobolo antigua con su pabellón fino de macana de Quito"-, que resaltaría la presencia de la marquesa. Además se encontraba un biombo de ocho hojas decorado con pinturas, una tarima grande cubierta con un petate y una alfombra pequeña que se ubicaba delante de la cama, una mesa pequeña con cubierta de azafate negro de la China, una silla poltrona tapizada con baqueta, dos taburetes ingleses con respaldos de rejilla, cuatro taburetes recubiertos con cuero, una mesa redonda de cuatro pies, una caja colorada y claveteada de la China, y un escritorio negro con chapas y tiradores de metal de la China y dos baulitos de carey embutidos de concha de perla con chapas y llaves de plata dentro de los cuales se encontraban finas alhajas.

La recámara en cambio, era un espacio destinado a las criadas de la señora. Allí tenían sus camas y cajas con sus pertenencias, junto con cajas y un escaparate de acabado fino (con aplicaciones de chapas de plata) con objetos de la marquesa, como su ropa de uso y de cama, manteles y servilletas, vajilla de plata, y piezas de loza, cristal, lata y marfil.

Un aspecto que destaca es el gusto de la marquesa por los productos orientales o chinescos, de especial auge en el siglo XVIII y característicos del gusto rococó francés. La mayoría presentaban un acabado oscuro, por lo que suponemos que se trataba de muebles lacados con aplicaciones de metal, decoración acorde con el estilo oriental ${ }^{17}$. Además de los ya mencionados, se encuentran en su inventario otros objetos expresamente indicados

17Una técnica que causó gran efecto en el mobiliario europeo fue la del laqueado japonés, del que surgieron en seguida imitaciones europeas. Este hecho "(...) tuvo su importancia estilística, puesto que los artesanos orientales proporcionaron a los europeos un repertorio completo y original de diseños exóticos (...)." (LucieSmith, 1980: 73). En España, “la enorme afluencia del comercio con Oriente a través de las Indias Occidentales primero y directamente después por el establecimiento de firmas comerciales holandesas e inglesas en España, en la que se traían infinidad de muebles lacados y la creación de talleres americanos destinados al tratamiento de este material (...), hizo que quedaran en el olvido las piezas traidas directamente en la segunda mitad del siglo XVI (...)." (Aguiló, 1993: 133). Como muebles "de la China”, por lo tanto, se puede considerar a piezas realizadas en Oriente y, más probablemente, a ejemplares realizados a imitación de los orientales. 


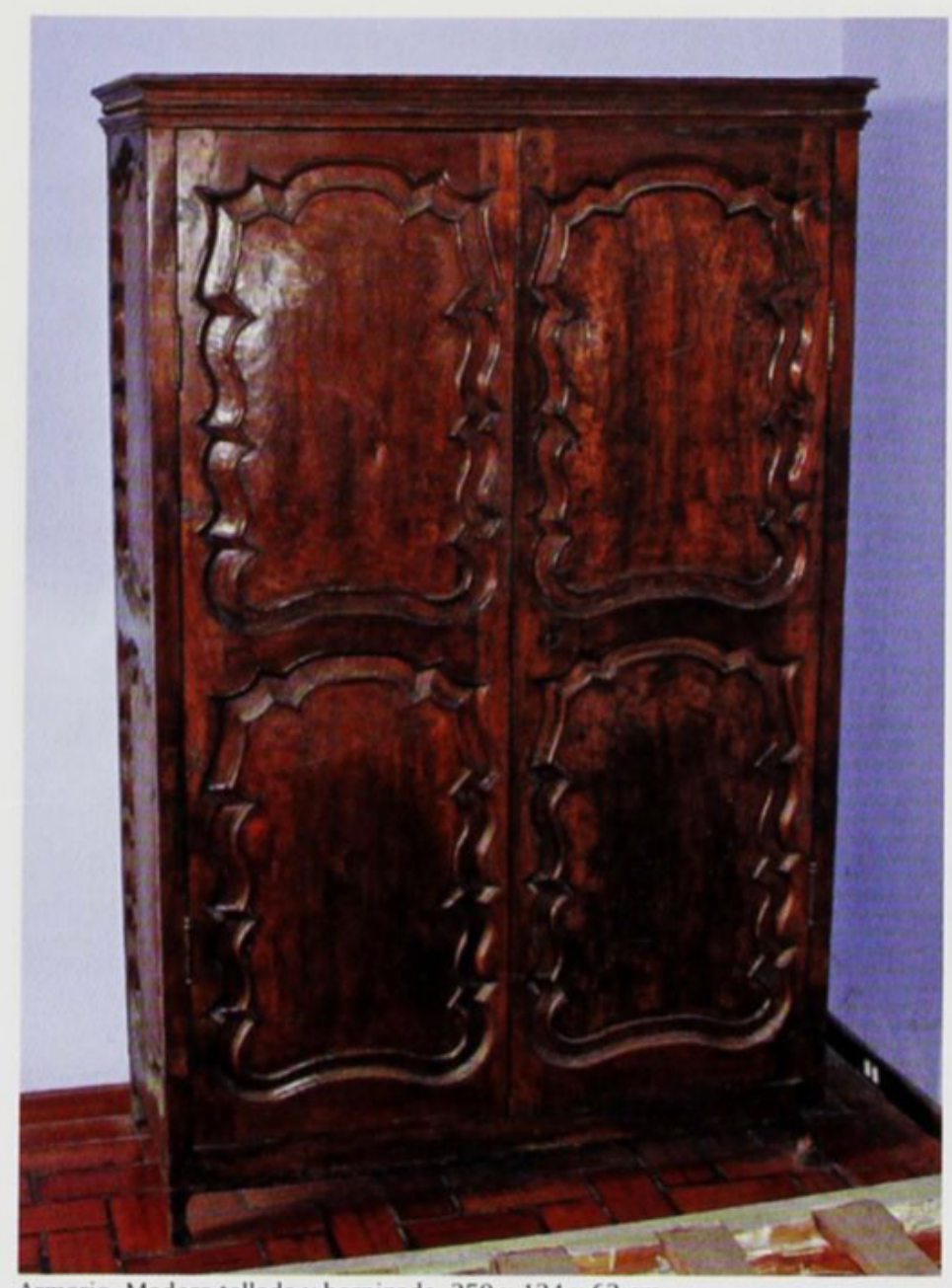

Armario. Madera tallada y barnizada. $250 \times 124 \times 62 \mathrm{~cm}$. Colección Quinta Presa - INC. como "de la China" como vajilla de loza, adornos en forma de perros y leones del mismo material, un sobrecama azul bordado de seda, una frasquerita y un tibor $^{18}$.

La introducción del gusto por el mobiliario inglés, que se había puesto de moda en Europa desde mediados del sigo XVIII y que llegó al virreinato del Perú recién a fines de este siglo, se refleja también en el inventario de la marquesa en la existencia de dos taburetes ingleses con sus respaldos de rejilla. Si bien desde inicios del siglo XVIII se constata la presencia de mobiliario de este tipo en las casas limeñas acomodadas producto del contrabando, el ingreso en grandes cantidades de este tipo de muebles coincide con el tratado de libre comercio que decreta la corona Española en $1778^{19}$.

La vivienda de doña María Ignacia Carrillo y Garcés, condesa de

Vistaflorida, estaba ubicada en la calle que va de la pileta de Nuestra Señora de la Merced hacia el convento de San Juan de Dios en la ciudad de Lima. La disposición y ubicación de los muebles también es significativa para comprender el modo de vida de las mujeres de la aristocracia del siglo XVIII.

Las habitaciones que resaltan por su decoración y por el detalle con que han sido descritas, son la cuadra de estrado, el cuarto de dormir y las recámaras. La coincidencia de estos espacios con los anotados en el inventario de la marquesa de Torre Tagle, señala claramente que las actividades de las mujeres se desarrollaban en espacios bien definidos de la casa, destacando la cuadra de estrado y la cuadra de dormir, ambos espacios de recibo, profusamente ornamentados y ricamente amoblados en correspondencia con su alto rango social, y las recámaras, en donde guardaban sus artículos de uso personal y objetos asociados al entorno doméstico como la vajilla de plata y porcelana y los adornos de este mismo material.

La cuadra de estrado de la condesa de Vistaflorida estaba forrada en damasco amarillo y verde y disponía de dos alfombras grandes. Las paredes estaban decoradas con cuatro espejos grandes y dos chicos, y se encontraban exquisitos objetos como diez cornucopias

18Las frasqueritas son pequeñas cajas con compartimentos para guardar y transportar frascos. Los tibores son grandes vasijas de cerámica o porcelana decoradas exteriormente, de procedencia china o japonesa.

$19 “(. .$.$) Inglaterra crea en este tiempo un tipo de mobiliario más sencillo que se adapta mejor al gusto español. Al$ principio, los muebles y telas ingleses entran de contrabando. Más tarde al liberalizarse el comercio, los barcos ingleses viene cargados de relojes, porcelanas, lozas y sillones y mesas Chippendale o Sheraton. (...)." (Aguiló, 1987: 311). 
de cristal, dos relojes, tres arañas de cristal y siete tibores. Esta demostración de riqueza se complementa con el tipo de muebles que allí se encontraban, destinados específica y únicamente a este ambiente de la casa, resaltando por su decoración y número las papeleras y los escritorios, que en la época se consideraban los muebles más ricos por los materiales con que estaban hechos (las cinco papeleras presentan un acabado barnizado en charol y los dos escritorios son enconchados). También se detallan cuatro cajitas embutidas de carey y concha de perla sobre unas mesitas con igual decoración, y veintidós taburetes forrados en terciopelo carmesí. Se puede comprobar la similitud en la decoración y el tipo de mobiliario presentes con los de la cuadra de la marquesa de Torre Tagle.

En el cuarto de dormir de la condesa de Vistaflorida se encontraba una cuja de cocobolo adornada con una colgadura de damasco carmesí (que en el inventario está almacenada en la segunda recámara), mueble suntuoso que concuerda con la costumbre indicada anteriormente de recibir a los invitados en la cama. Esta función de recibo se encuentra, además, corroborada en este caso por la presencia de numerosos asientos -un canapé y catorce taburetes forrados en damasco carmesí, haciendo juego con la cama-. Completan el amoblado un armario de caoba y un gran biombo de diez hojas decorado con pintura al óleo. Este último nos remite nuevamente al inventario de la marquesa de Torre Tagle, en cuyo dormitorio presenta un mueble similar, indicándonos presumiblemente el uso generalizado de este tipo de mueble en las habitaciones y probablemente también como signo de distinción.

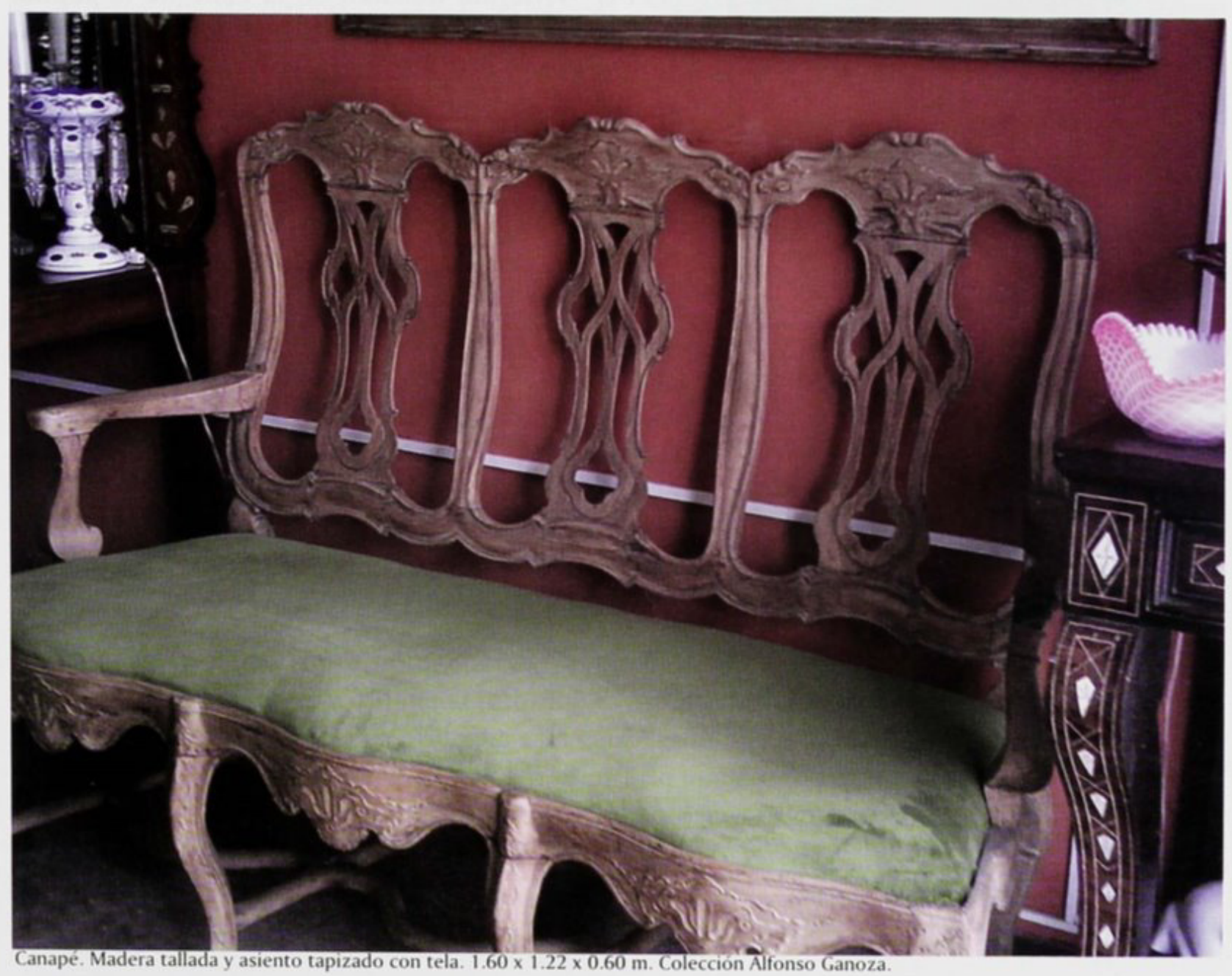


Relacionados con el cuarto de dormir se presentan dos habitaciones (la primera y la segunda recámara) en las que se encuentran sobre todo muebles para guardar, como cajas y escaparates, y en los que probablemente (no lo indica el inventario) se almacenaban tanto la ropa de cama y de vestir de la condesa, como la vajilla de plata y de loza, como era costumbre en la época (y tal como se registra en el inventario de la marquesa de Torre Tagle). Completan el amoblado de la primera recámara cuatro taburetes con asientos de Filipinas y el de la segunda, dos cajitas de madera con guarniciones de bronce y dos mesitas embutidas en concha de perla.

\subsection{El universo masculino al interior de la vivienda}

En el inventario de don Nicolás de Tagle Bracho, segundo conde de la Casa Tagle (1775), encontramos los bienes que se hallaban en su casa, ubicada en la calle siguiente de la puerta falsa del convento de San Agustín en dirección al Monasterio de Nazarenas ${ }^{20}$. Lo primero que resalta en el inventario es que sólo se especifica los bienes del cuarto de estudio, los demás objetos están dispuestos en una lista denominada "en otros espacios de la casa". Esto nos indicaría la importancia que tenía este espacio. En él se encontraba principalmente un lujoso catre (con cortinajes, rodapiés y dosel realizados en finas telas), probablemente debido a la costumbre de recibir a las visitas en la cama en determinadas ocasiones. Completan el mobiliario cinco sillas, un canapé y dos mesas con cajones con tiros y chapas de plata.

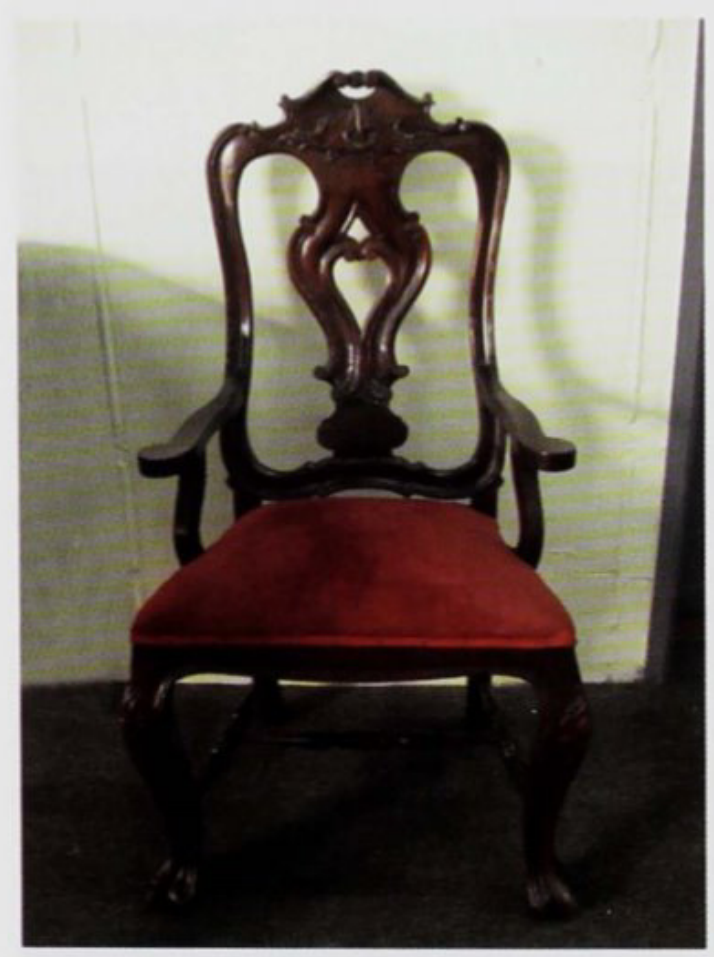

Silla de brazos. Madera tallada y barnizada, asiento tapizado con tela. $118 \times 64 \times 57.5 \mathrm{~cm}$.

Colección Quinta Presa - INC.

El inventario de los bienes de la residencia de don Gerónimo Angulo, conde de San Isidro (1771) -vivienda ubicada en la calle de la capilla de Monserrate ${ }^{21}-$, puede considerarse una contraparte del de la marquesa de Torre Tagle. En él sólo se indican los cuatro espacios de la casa en donde estaban ubicados sus bienes, sugiriendo las áreas de la casa destinadas a las funciones masculinas: la pieza de estudio, la cuadra y el cuarto de dormir además de la sala, ésta sí un espacio de recibo compartido por hombres y mujeres. La pieza de estudio es una habitación para funciones exclusivamente masculinas -una especie de despacho o escritorio-; la cuadra debía ser un espacio diferente a la cuadra de estrado de uso femenino y el cuarto de dormir que, según las costumbres de la época, era independiente del cuarto de dormir de la señora de la casa y en el que cada uno recibía a sus invitados.

Las tres habitaciones más decoradas y que presentan los muebles de mayor riqueza son el estudio, la cuadra y el cuarto de dormir. En las dos primeras se hallan varias papeleras (dos en la pieza de estudio y dos en la cuadra) y escritorios (dos en la cuadra), además de una serie de asientos (varios taburetes y una silla) y en el estudio hay también un guardarropa y una mesa grande. Entre los adornos, ambas

20Inventario de Bienes de Don Nicolás de Tagle Bracho, segundo Conde de Casa Tagle. AGN, Protocolos, Phelipe Jusepe Jarava, $\mathrm{N}^{\circ} 558,1774-1775$, ff. $426-443$.

21 Inventario y Tasación de Bienes del Conde de San Isidro. AGN, Protocolos, Juan B. Thenorio Palacios, $\mathrm{N}^{\circ} 1018,1771$ 1772, ff. 386-452. 
habitaciones presentan espejos, láminas de diversas advocaciones con marcos dorados o de plata, cornucopias de cristal y un reloj; el estudio presenta además cuatro lienzos y la cuadra cuatro tibores de la China, una alfombra y dos arañas de cristal. En el cuarto de dormir hay una variedad de asientos (taburetes, sillas poltronas, canapés), un armario, una cómoda, dos tocadores, una cama imperial, las dos papeleras más ricas de la casa (enconchadas de nácar), una mesita enconchada y una mesita de plata. Entre los adornos se encuentran varias láminas con marcos de plata o de cristal, tres espejos con marcos dorados y una araña de cristal.

Finalmente el inventario de los bienes de don José González Gutiérrez, primer conde de Fuente González (1806), en su residencia ubicada en la calle de Valladolid ${ }^{22}$, nos introduce también al universo masculino al interior de las viviendas de la época. Así como en el inventario del conde de San Isidro, los espacios en donde se encontraban sus bienes eran el estudio, la sala, el cuarto de dormir y la cuadra -a los que se añaden las recámaras y el comedor-. Queremos destacar los muebles que se encuentran en el estudio, a través de los que se resalta la función de este espacio como despacho o escritorio: cuatro mesas carpetas, dos mesas doradas, un estante grande, un estante para papeles y un estante para libros, tres papeleras de dos cuerpos con lunas azogadas y herrajes de plata (en uno de los casos se especifica que el segundo cuerpo sirve como estante para

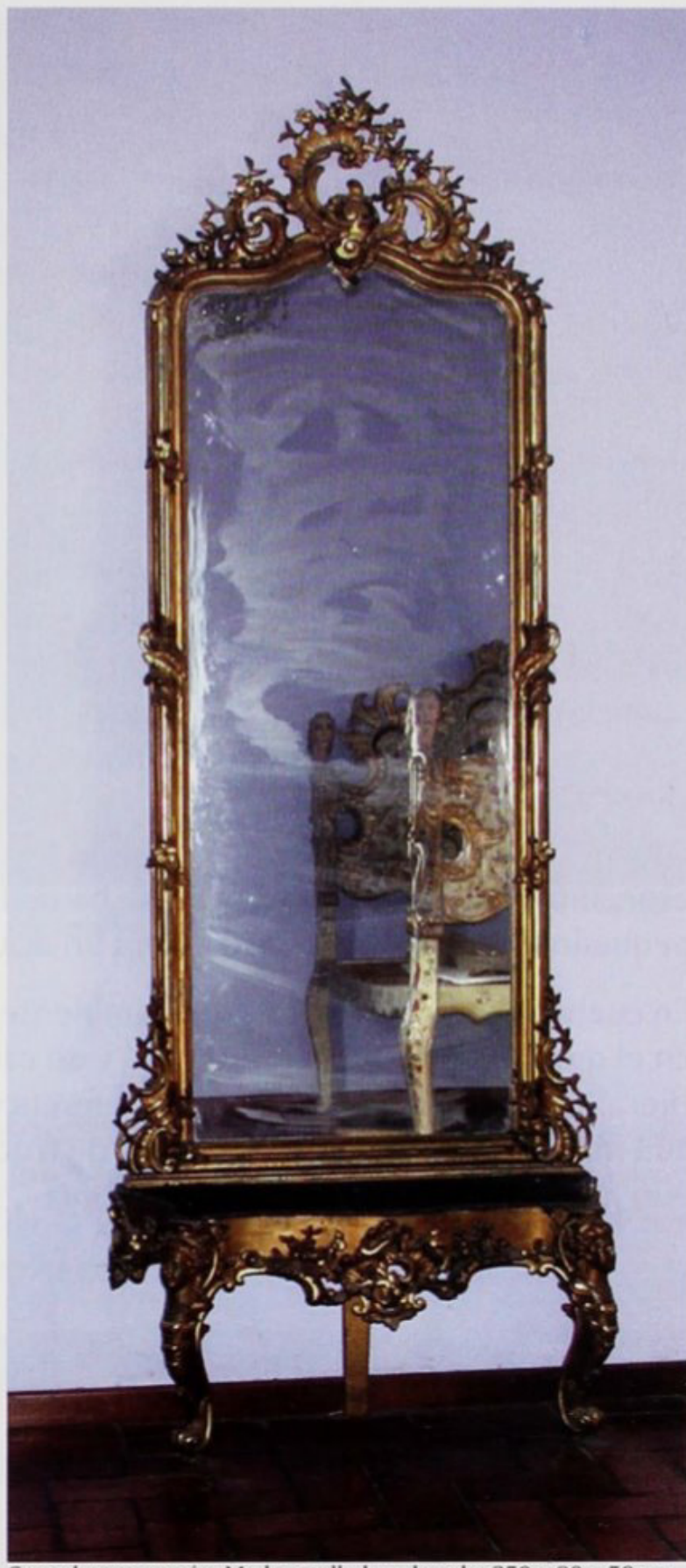

Consola con espejo. Madera tallada y dorada. $250 \times 90 \times 50 \mathrm{~cm}$. Colección Quinta Presa - INC.

libros), una mesa grande para escribir, dos mesitas esquineras, un sofá forrado en damasco, una silla poltrona forrada con terciopelo carmesí y tres bancos forrados con badana.

\section{El modo de vida en una casa de descanso: la Quinta Presa}

El inventario de bienes de don Pedro Carrillo de Albornoz (1798), comprende las pertenencias de la Quinta Presa ${ }^{23}$. De este se desprende que el inmueble se componía de un primer cuarto o cuarto de estudio, un segundo cuarto o tras estudio, un oratorio, una sala, una cuadra, un cuarto de dormir, un comedor alto, recámaras, un cuarto para la fruta, una cocina alta, una pieza subsecuente, dos cuartos al costado, una pieza baja, un comedor bajo, un cuarto de repostería, el traspatio, la cocina y anexa a ella una despensa, un cuarto

22Inventario de Bienes del Conde de Fuente Gonzalez. AGN, Real Audiencia. Causas Civiles, leg. 69, cuad. 674, año 1806.

23 Dumbar Temple, 1948: 344-374. 
en el patio principal, dos piezas más en dicho patio, un salón grande, una cochera, las habitaciones de los criados en el entresuelo sobre la cochera y un galponcillo de cuatro piezas para los esclavos.

Lo primero que podemos notar respecto a los muebles inventariados es que, a pesar de tratarse de una familia de la clase alta, el tipo de mobiliario difiere bastante de los modelos anotados anteriormente. Esto puede deberse, en primer lugar, a que don Pedro Carrillo de Albornoz era un personaje de evidente gusto afrancesado, ya que la quinta es uno de los mejores ejemplos de arquitectura rococó que se encuentra en Lima, y en segundo lugar, a que no se trata de su lugar de residencia, como en los otros casos tratados en este ensayo, sino de una casa de descanso, en la que la rigidez de la etiqueta y el deber de ostentación debieron haber sido menores.

En cuanto a los muebles, lo primero que llama la atención es su decoración, ya que si bien la mayoría presenta algún tipo de ornamento, éste no suele ser muy rico. Así, entre los asientos predominan los taburetes de sauce pintado con asientos de paja, y en menor número se encuentran los taburetes forrados en terciopelo, algunos con bordado de plata, en tafilete y en baqueta. Entre las mesas predominan las de tijeras forradas en paño verde, aunque también hay una forrada en baqueta y una embutida. El embutido sólo lo encontramos además en dos pequeñas cómodas y en un armario grande, aunque no se especifica el material con el que se ha realizado la incrustación. Asimismo, cinco estantes pequeños y cuatro catres presentan un acabado barnizado.

En cuento a los amoblados de los ambientes de la quinta, es interesante destacar el estudio en el que sólo encontramos un sofá y un canapé, diez taburetes pequeños y dos mesitas de tijera, ninguno de los cuales hace referencia a que allí se realizara algún tipo de trabajo, y aún más, en él se hallaba una mesita de truco con sus seis taquitos y cuatro bolitas de marfil -un juego bastante común en la colonia-, señalando su carácter de casa de descanso.

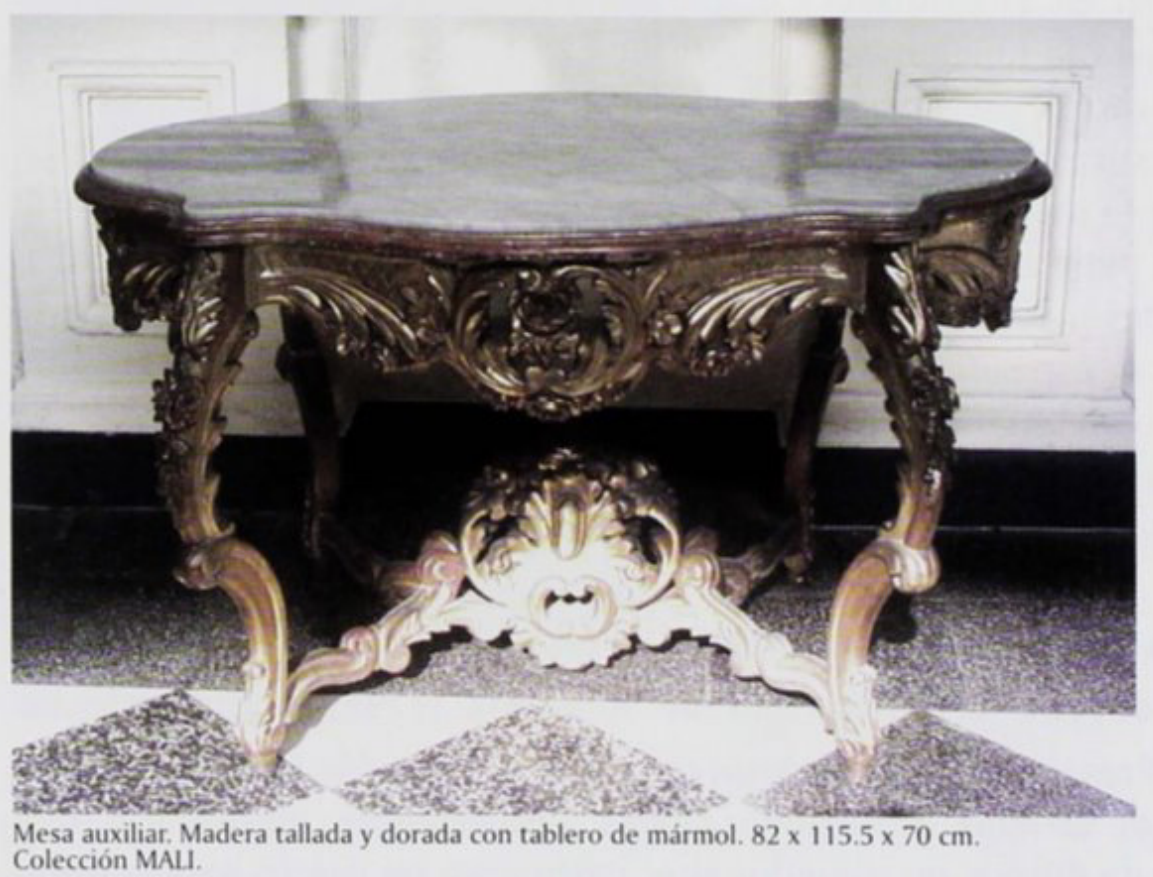

De los muebles detallados, hay que indicar que el sofá y las cómodas son dos tipos de muebles que sólo se hallan en las relaciones de bienes de los últimos años del siglo XVIII y que corresponden a un gusto más afrancesado en la decoración de interiores. Asimismo, destacan por su número, los taburetitos de sauce pintado con asientos de paja que se encuentran prácticamente en todas las habitaciones prin- 
cipales de la casa, y que denotan también el gusto por los muebles pintados característicos de la decoración rococó dieciochesca.

Entre los asientos destaca también un juego de rica decoración que se halla en la cuadra, se trata de cuatro sillas poltronas que hacen juego con cinco taburetes forrados en terciopelo carmesí bordados con plata. Otro mueble que se encuentra en gran cantidad y en casi todas las habitaciones principales son las mesas denominadas como "de movimiento para camino" y que en la tasación se denominan como "de tijera" -es decir, se trataría de muebles plegables y portátiles-, las cuales están mayoritariamente forradas en paño verde.

Los catres parecen ser muy sencillos,

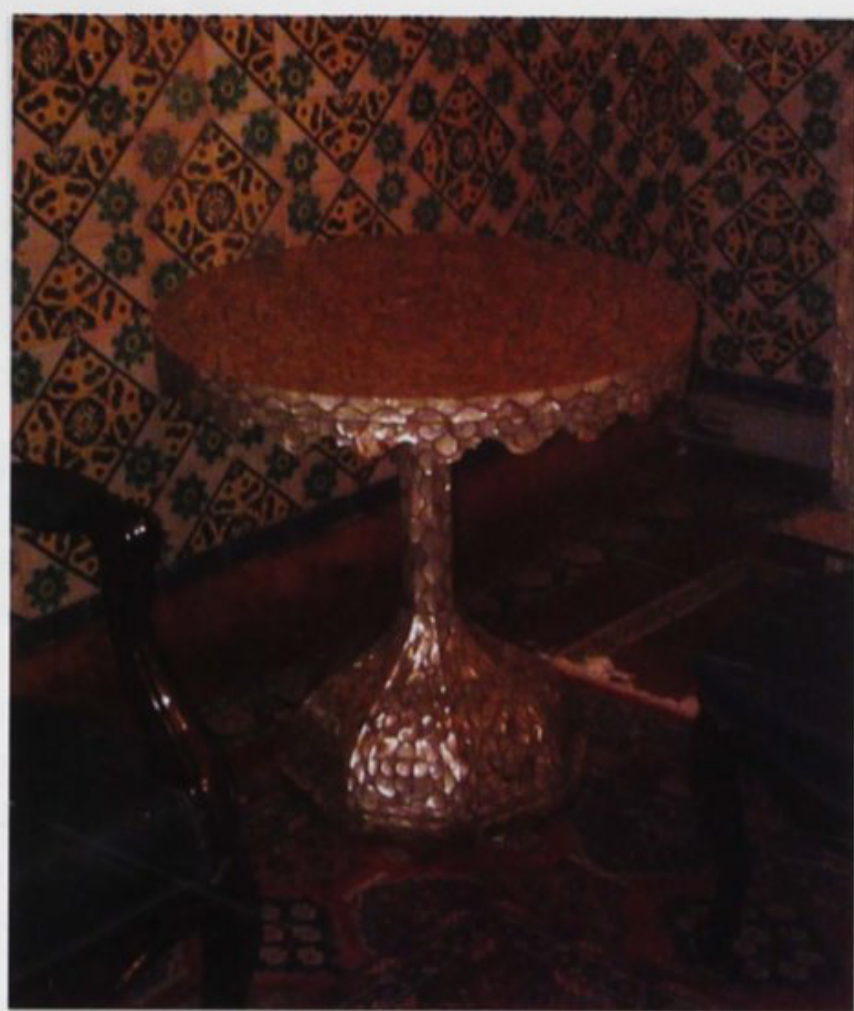

Mesita auxiliar. Madera tallada y enconchada. $\emptyset 50 \times 70 \mathrm{~cm}$. Colección Palacio de Torre Tagle - Ministerio RR.EE.

siendo la mayoría barnizados, presentando uno de ellos un marco dorado y tres con una toldilla pintada

al óleo. Entre los muebles para guardar no se encuentran cajas ni cajones -que van desapareciendo del mobiliario hacia fines de siglo-, y más bien encontramos un armario y tres alacenas destinados principalmente a guardar la vajilla, y cinco estantes, uno de ellos para vajilla y los otros para libros.

La decoración de las principales estancias se describe claramente en el inventario. Habitaciones como el cuarto de estudio, la sala, el cuarto de dormir y la glorieta presentan paredes decoradas con papel pintado y el cielo raso pintado al óleo; el tras estudio y los comedores alto y bajo sólo lucen pintura al óleo en el cielo raso; y las paredes de la cuadra están tapizadas con terciopelo carmesí bordado con plata en juego con el tapizado de las sillas poltronas y los taburetes que en ella se encuentran. Se trata, en general, de modos de decoración -las paredes pintadas, los juegos de mobiliario- más acordes a los gustos del siglo XVIII europeo.

\section{El mobiliario en la casa de un alto funcionario del gobierno}

Don Cristóbal Francisco Rodríguez, Administrador General de Temporalidades era un alto funcionario del gobierno, cuyo puesto, así como el de los encargados de los corregimientos, audiencias o el ejército, estaba muy bien considerado dentro de la sociedad colonial. No hay que olvidar, además, que por lo general eran sólo las personas convenientemente posicionadas en este entorno quienes accedían a estos cargos.

Según su inventario $(1789)^{24}$, su casa ubicada en la calle de San Marcelo, presentaba una gran cantidad de muebles, cuya tipología es muy similar a los que observamos en los

\footnotetext{
${ }^{24}$ Inventario de bienes de la casa y oficina de Don Cristóbal Francisco Rodríguez. AGN Temporalidades Inventarios. Inv. 4, Doc. 10. Legajo 4, Cuaderno 83, Año 1789, $56 \mathrm{ff}$.
} 
inventarios de bienes de los nobles del último tercio del siglo XVIII. Esto se explica porque si bien Rodríguez no era noble de título, debía al igual que éstos, demostrar su elevada posición social.

En algunos casos, sin embargo, podemos observar que los muebles son de materiales menos costosos. El caso de los asientos es bastante claro. Si bien algunos taburetes estaban forrados en finas telas como el terciopelo carmesí, otros estaban forrados con tripe -tejido de lana parecido al terciopelo-, asimismo las sillas estaban tapizadas de manera más sencilla con suela prensada y cordobán negro, y los canapés con baqueta. Otro ejemplo es el de los armarios, muebles por lo general profusamente ornamentados, que en este caso no presentan decoración.

Llama la atención en este inventario, dos hechos: por un lado la falta de camas, y por otro la presencia de repisas y alacenas, éstos últimos dos tipos de muebles que no se encuentra en ninguno de los inventarios revisados. Sobre las repisas no se indica ninguna característica, salvo que están realizadas en materiales relativamente

finos (cinco imperiales doradas, dos con cortinas de filipichín -tela de lana estampada- y cinco de tabla de Chile) y que están ubicadas, como es de suponerse por su calidad, en los lugares de recepción. En cuanto a las alacenas, se indica en el inventario que se trata de muebles de firme o embutidos en la pared -es decir, son muebles empotrados-, que contienen vajilla, libros y ropa del uso del señor y de sus hijas, y están ubicadas en el cuarto de dormir, en la recámara y en el cuarto de estudio.

Además de en las alacenas, la vajilla y la ropa se guardaban, como se refiere en los otros inventarios, en los armarios, guardarropas y cajas. Pero hay que señalar que en las papeleras, además de los libros y papeles, también se guardaba ropa y vajilla, por lo que suponemos que se trataba de los muebles de dos cuerpos muy usados en Europa en esta época, en los que la parte superior de puertas laterales con lunas de cristal servía para los libros y papeles, y la parte inferior, compuesta por grandes cajones, para los otros tipos de objetos.

\section{Conclusiones}

La disposición de los muebles y la decoración en general de los interiores de cada una de las habitaciones de las casas de los personajes que formaban parte de los más altos estratos de la sociedad colonial del siglo XVIII refleja y permite visualizar una serie de características de su modo de vida y de su comportamiento privado y social. De este modo, los muebles más ricamente decorados se ubicaban en los espacios de recibo, ya que los dueños de estas viviendas debían demostrar frente a los demás su elevado estatus social y ser tratados con la correspondiente distinción. Asimismo, las diferencias de

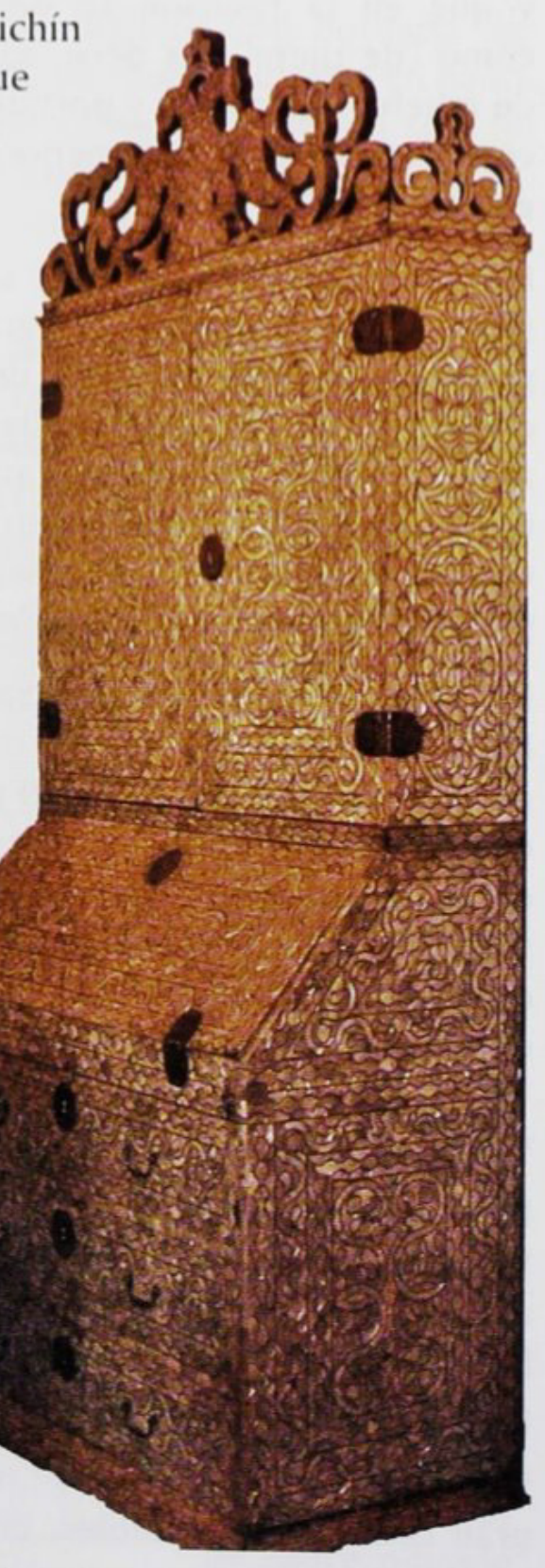

Escritorio-papelera. Madera tallada y enconchada. $240 \times 100 \times 40 \mathrm{~cm}$. Colección Palacio de Torre Tagle - Ministerio RR.EE. 
género eran perceptibles en el uso preferente de determinadas habitaciones por las mujeres y los varones, $y$ en la disposición en ellas de determinados muebles acordes con las actividades y funciones que en ellas se realizaban.

Por otro lado, se aprecian distinciones en el mobiliario y en la decoración de las viviendas entre los diferentes rangos de la clase dominante, debido a aspectos como las funciones protocolares que debian tener algunas habitaciones del palacio de gobierno, las prerrogativas debidas al estatus, género, ubicación y/o actividad principal de las casas de los nobles comerciantes, y a los distintivos de rango que debía mostrar un alto funcionario de gobierno.

A través de los inventarios post-mortem aquí revisados, que recorren todo el siglo XVIII -desde el de Castelldosrius de inicios del siglo XVIII hasta el del conde de Fuente González de inicios del siglo XIX-, es posible mostrar los cambios en los gustos y modas a lo largo del tiempo, desde una preferencia por el estilo barroco, que venía de un fuerte desarrollo en el siglo XVII y perdura de manera bastante sostenida hasta mediados del siglo XVIII, a una introducción cada vez mayor, aunque siempre restringida, de modelos correspondientes al rococó francés. Los muebles de estilo barroco como sillas, taburetes, canapés, baúles y cofres recubiertos con baqueta, así como escritorios, armarios, grandes mesas, bancos y escaños profusamente tallados, fueron dando paso a ejemplares de estilo rococó, más livianos y sencillos como sillas, taburetes, sofás y canapés tapizados con telas, escritorios y cajitas de acabados lacados o embutidos con finos materiales, y mesas pequeñas, consolas, esquineros, estantes, repisas, papeleras y alacenas de tallas moderadas.

\section{Referencias Bibliográficas}

Aguiló, María Paz. "Mobiliario", en: Bonet Correa, Antonio (coord.), Historia de las artes aplicadas e industriales en España, Madrid: Cátedra, 1987.

El Mueble en España, siglos XVI-XVII. Madrid: C.S.I.C., 1993.

Bennett Oates, Phyllis. Historia dibujada del mueble occidental, Madrid: Hermann Blume, 1984.

Calderón, Gladys. La Casa Limeña. Espacios habitados, Lima, 2000.

Cucco, Vanesa. Diccionario del mueble. Madrid: Editorial LIBSA, 2003.

Dunbar Temple, Ella. "El Inventario de la Quinta Presa”, en: Documenta. Revista de la Sociedad Peruana de Historia, Año I, N ${ }^{\circ} 1$ (1948), Lima, pp. 317-374.

Elias, Norbert. La Sociedad Cortesana, México D.F.: Fondo de Cultura Económica, 1982.

El proceso de la civilización. Investigaciones sociogenéticas y psicogenéticas. México D. F.: Fondo de Cultura Económica, 1987.

Junquera y Mato, Juan José. “Mobiliario”, en: Bartolomé Arraiza, Alberto (coord.), Las artes decorativas 
en España, T. II. Summa Artis. Historia General del Arte, T. XLV, Madrid: Espasa-Calpe, 1999.

Lencina Pérez, Xavier. "Los inventarios post-mortem en el estudio de la cultura material y el consumo. Propuesta metodológica. Barcelona, siglo XVII." En: Consumo, condiciones de vida y comercialización. Cataluña y Castilla, siglos XVII-XIX. Junta de Castilla y León - Consejería de Educación y Cultura, 1999. pp. 41-59.

Lucie-Smith, Edward. Breve Historia del Mueble, Barcelona: Ediciones del Serbal, 1980.

Mazzeo de Vivó, Cristina Ana. "El comercio libre de 1778 y sus repercusiones en el mercado limeño", en: O'Phelan, Scarlett (comp.), El Perú en el siglo XVIII. La Era Borbónica, Lima: IRA-PUCP, 1999, pp. 127-145.

Los comerciantes limeños a fines del siglo XVIII. Capacidad y cohesión de una élite 1750-1825. Lima: PUCP -Dirección Académica de Investigación, 2000.

Sala i Vila, Nuria. "La escenificación del poder: el marqués de Castelldosrius, primer virrey Borbón del Perú (1707-1710)". En: Anuario de Estudios Americanos, Vol. 61, Núm. 1. Sevilla: C.S.I.C. Escuela de Estudios Hispano-Americanos, 2004, pp. 31-68.

Yun Casalilla, Bartolomé. "Inventarios post-mortem, consumo y niveles de vida del campesinado del Antiguo Régimen. Problemas metodológicos a la luz de la investigación internacional". En: Consumo, condiciones de vida y comercialización. Cataluña y Castilla, siglos XVII-XIX. Junta de Castilla y León Consejería de Educación y Cultura, 1999, pp. 27-40. 